\title{
Mechanisms for Spreading of Mediterranean Water in Coarse-Resolution Numerical Models*
}

\author{
R. Gerdes, C. Köberle, And A. Beckmann \\ Alfred-Wegener-Institute for Polar and Marine Research, Bremerhaven, Germany \\ P. HERRMANN AND J. WiLlebrand \\ Institut für Meereskunde, Kiel, Germany
}

(Manuscript received 20 May 1997, in final form 27 July 1998)

ABSTRACT

\begin{abstract}
Different processes have been proposed to explain the large-scale spreading of Mediterranean Water (MW) in the North Atlantic, however, no systematic study comparing the efficiency of different processes is yet available. Here, the authors present a series of experiments in a unified framework that is designed to quantify the effects of several physical processes on the spreading of MW in an idealized model of the North Atlantic. The common technique of restoring temperature and salinity to an observed distribution near the Mediterranean inflow fails to produce an adequate amount of MW because the eastern boundary region near the MW inflow is rather quiescent in models. Diapycnal processes like double diffusion and cabbeling turn out too inefficient to alone account for the large-scale MW anomaly. However, with a preexisting anomaly, double diffusion leads to a considerable northward and zonal redistribution of MW. The density anomaly induced by cabbeling curtails the zonal spreading of MW while it increases the northward spreading. With isopycnal mixing and the weak mean flow that prevails in the outflow region, a spatial distribution of the MW anomaly is obtained that is inconsistent with observations. Unrealistically high diffusion coefficients would be necessary to reproduce the observed salt flux into the Atlantic. The most effective process in the experiments is the volume flux associated with the Atlantic-Mediterranean exchange. The current system that is established in response to the inflow of MW into the Atlantic carries the anomaly almost $30^{\circ}$ of longitude into the basin and along the eastern margin up to the northeastern corner of the domain and farther along the northern boundary.
\end{abstract}

\section{Introduction}

The Mediterranean salt tongue is one of the outstanding features of the North Atlantic hydrography. At a depth of 1000-1200 $\mathrm{m}$ it extends westward from the Gulf of Cadiz almost across the whole Atlantic basin. Along the eastern margin it can be traced far into the northern North Atlantic. The distinct silicate signature of the Mediterranean Water (MW) indicates its presence as far north as the Norwegian Sea. This observation brought Reid (1979) to the conclusion that the Mediterranean outflow helps to maintain the high salinity of the Norwegian Sea and thus sets the condition for deepwater formation in the northern North Atlantic. He argued that the Mediterranean Water has a profound effect

\footnotetext{
* Alfred-Wegner-Institute Contribution Number 1435.
}

Corresponding author address: Dr. Rüdiger Gerdes, Alfred-Wegener-Institute for Polar and Marine Research Am Handelshafen 12, D-27570 Bremerhaven, Germany.

E-mail: rgerdes@AWI-Bremerhaven.DE on the general circulation of the global ocean through its influence on deep-water formation. In a series of idealized global ocean models Cox (1989) included a source of saline water corresponding to the Mediterranean outflow in the Atlantic basin. This source of saline water enabled North Atlantic Deep Water (NADW) to penetrate deeper and farther to the south with its influence extending right across the Southern Ocean and into the Indian and Pacific basins. Irrespective of the exact distribution and pathways of MW in the Atlantic, the influence on the salt budget is clearly significant. According to Bryden and Kinder (1991) the exchange through the Straits of Gibraltar corresponds to a net evaporation of $0.56 \mathrm{~m} \mathrm{yr}^{-1}$ over the surface area of the Mediterranean of $2.52 \times 10^{6} \mathrm{~km}^{2}$. The surface water flux of $0.045 \mathrm{~Sv}\left(\mathrm{~Sv} \equiv 10^{6} \mathrm{~m}^{3} \mathrm{~s}^{-1}\right)$ is $17 \%$ of the total net surface water flux of $0.26 \mathrm{~Sv}$ estimated for the entire North Atlantic between the equator and $65^{\circ} \mathrm{N}$ (Wijfels et al. 1992).

From the $0.7 \mathrm{~Sv}$ inflow of pure MW (at salinity 38.4 psu) and its salinity elevation of 2.8 above the surrounding Atlantic water (Ochoa and Bray 1991) we calculate a salt flux of $62 \mathrm{Gt} / \mathrm{yr}$ that feeds the large-scale 
MW anomaly in the Atlantic. If we define MW in the North Atlantic as water below $800 \mathrm{~m}$ with salinities higher than $35.25 \mathrm{psu}$, we arrive at a salt anomaly of $10^{15} \mathrm{~kg}$ of the MW in the Atlantic. This implies a timescale of MW renewal of $O(20 \mathrm{yr})$ unless a large fraction of MW spreads to higher latitudes where, due to deep water mass formation, it loses its identity of Mediterranean origin. We do not know how large this fraction is in the ocean, but any mechanism to explain the spreading of MW must be efficient enough to establish the MW within a time period of a few decades.

Mediterranean Water spreading in the Atlantic is believed to be accomplished by large-scale advection and diffusion with isolated lenses of undiluted MW (meddies) acting as moving point sources (Armi and Haidvogel 1982; Käse and Zenk 1987). It is not obvious what drives the large-scale advection at the MW level. Ekman suction in the subpolar gyre causing northward middepth flow at lower latitudes has been proposed by Schopp and Arhan (1986). However, observations along the North Atlantic eastern boundary and the Rockall Channel (Arhan et al. 1994) indicate that northward slope currents are more likely to carry the bulk of the MW to high latitudes.

Price et al. (1986) hypothesize that the Mediterranean salt tongue does not act as a passive tracer but is dynamically active and may have important internal dynamics. Arhan (1987), for instance, observes a westward spreading of MW at 1000-m depth, while the MW tongue extends in a southwesterly direction at $1800-\mathrm{m}$ depth. He finds a corresponding rotation of the velocity vector with depth in an inverse model of the area. He conjectures that the associated vertical velocity is due to double diffusive mixing below the core of the MW. Injection of water masses at the eastern boundary and cross-isopycnal mixing in the salt tongue have been investigated by Tziperman (1987). In his model, diapycnal diffusion determines the dissipation of westward traveling Rossby waves and with that the westward distance traveled by the inflow before turning northward.

Eddy salt and heat fluxes have been considered by Spall (1994). He finds that eddy fluxes associated with low-frequency zonal motions caused by baroclinic instability in the Mediterranean outflow region may carry a considerable amount of salt and heat westward within the core of the Mediterranean salt tongue. Computing the flow perpendicular to a meridional section in the eastern North Atlantic by means of an inverse model, Arhan et al. (1994) indicate advective westward transport of MW between $38^{\circ}$ and $45^{\circ} \mathrm{N}$, while turbulent diffusion dominates elsewhere. This view is supported by several meddies that were sampled south of $37^{\circ} \mathrm{N}$. However, the quantitative role of meddies for the North Atlantic salt flux and their dynamic influence on the salt tongue is not well known. In a recent review article, Käse and Zenk (1996) estimate that 40 meddies per year would be needed to balance the salt flux at Gibraltar. This number is certainly higher than the actual number of meddies in the ocean. The transport of salinity anomaly due to meddies has been estimated to be approximately $20 \%$ of the total flux into the North Atlantic by Richardson et al. (1989).

Despite the apparent importance of the MW for the Atlantic water mass composition and circulation, only minor efforts have been made to properly represent the MW in general circulation models. The narrow and shallow connection between the Mediterranean and the Atlantic makes it difficult to explicitly simulate the exchange in large-scale models. Thus, some submodel or parameterization of the exchange has to be incorporated. Usually, a source of MW is implemented by a sponge layer near the inflow, where model variables are nudged toward observed water mass properties. Forcing the anomaly by applying the robust diagnostic technique introduced by Sarmiento and Bryan (1982) over the whole model domain, Stanev (1992) was able to produce the westward middepth current needed to spread the MW through the North Atlantic basin. However, prognostic models usually do not perform as well. In a comparison of observed large-scale hydrography and results from the NCAR CME (Community Modeling Effort: Bryan and Holland 1989) Model, Spall (1990) notes that model salinity decreases rapidly away from the eastern boundary with salinities in the interior of the Atlantic being far too low. The major restructuring of the MW from the observed climatology that serves as initial condition occurs during only $20 \mathrm{yr}$ of model integration. Klinck (1995) also analyzes the water mass assembly of the NCAR CME Atlantic model. The net salt flux out of a sponge layer between Spain and Morocco, which acts as the source of MW in that model, is smaller than the observed values by a factor of about 40 . The advective transport out of Gulf of Cadiz is insufficient due to the very slow mean currents at the eastern boundary and the MW depth.

In this paper we investigate different mechanisms that could contribute to MW spreading in a numerical model. We consider a large-scale model that does not explicitly resolve the processes involved in the outflow from the Mediterranean and the subsequent development of the plume over the continental slope. Our aim is to isolate individual mechanisms of MW spreading in the North Atlantic and to compare the effectiveness of different processes. The question whether the MW anomaly plays an active dynamical role will be considered. For this end we chose an idealized configuration for the model (described in section 2) and set up a number of sensitivity experiments with the same basic model. Each of the experiments addresses a single process. The experimental strategy and the injection and spreading mechanisms considered are presented in section 3 , which is supplemented by simple salt flux estimates for the different mechanisms in section 4. Model results in terms of salt fluxes into the Atlantic are presented in section 5 , which also examines the emerging salinity and flow patterns. In section 6 we discuss the results in compar- 


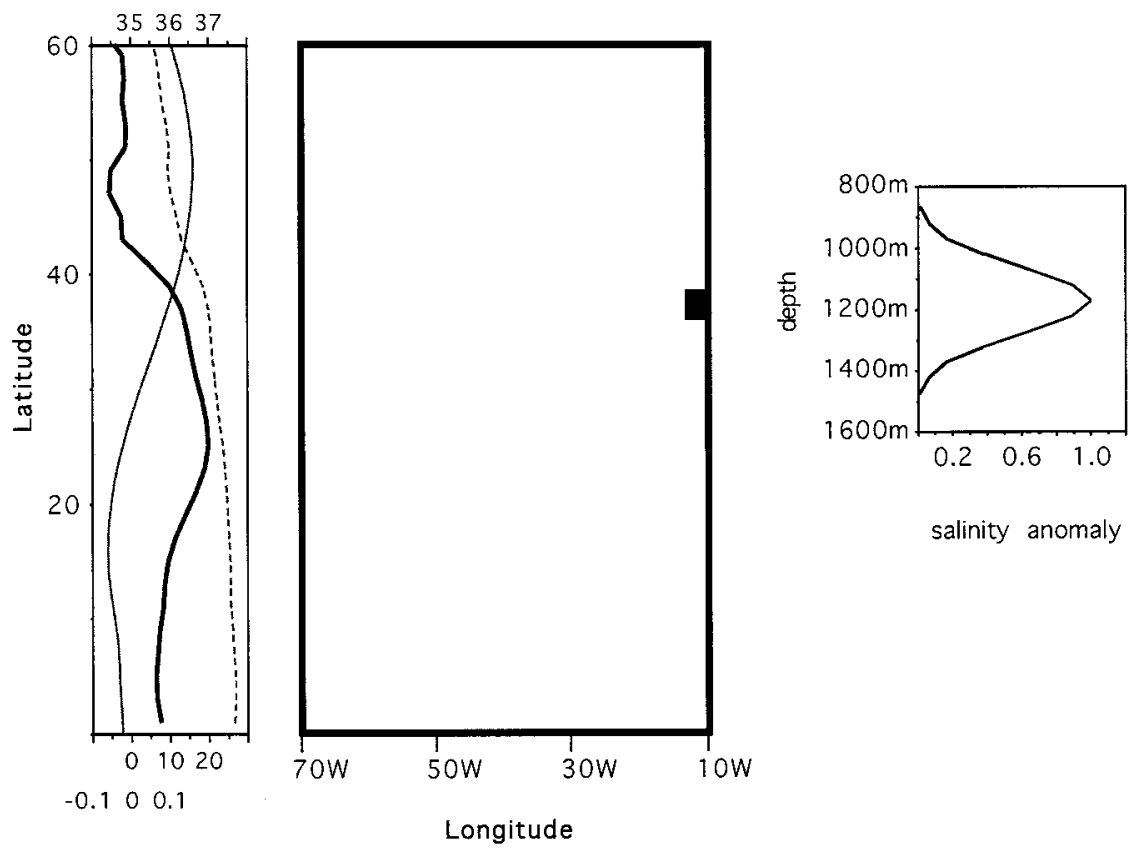

FIG. 1. Configuration of the model. Wind stress (solid line), reference surface temperature (dashed line), and salinity (heavy line) are zonally uniform and shown at the left of the model domain. Wind stress is given in Pa (lower axis labels), temperature in ${ }^{\circ} \mathrm{C}$, and salinity in psu (top axis labels). Mediterranean water is injected in one grid column at the eastern boundary, marked with a solid square. The salinity anomaly is shown at the right of the model domain as a function of depth.

ison with observed quantities and present our conclusions.

\section{Model}

The model is based on the GFDL primitive equation model MOM-1 (Pacanowski et al. 1991). The basic configuration is shown in Fig. 1. The model domain is a $60^{\circ}$ wide sector extending from the equator to $60^{\circ} \mathrm{N}$. A symmetry condition is employed at the southern boundary. The bottom is flat and the depth is $4000 \mathrm{~m}$. The horizontal resolution is $2^{\circ}$ in both directions, while we chose 50 levels in the vertical direction. The horizontal resolution is comparable to or better than the resolution of current climate models. Vertical grid distances are 60 $\mathrm{m}$ between the surface and 1800-m depth and gradually increase to a maximum of $160 \mathrm{~m}$ below. The vertical resolution is relatively high to better resolve water masses and represent diapycnal mixing processes like cabbeling and double diffusion. Increasing the vertical resolution only linearly increases the cost of a model because the time step is usually not limited by vertical processes. Thus higher vertical resolution is a practicable option for large-scale models, while an increase in horizontal resolution is often precluded by the cubic increase in computing time.

For most experiments the equation of state is linear and compressibility effects are ignored,

$$
\rho=\rho_{o}(1-\alpha \Theta+\beta S),
$$

where $\rho$ is the in situ density, $\Theta$ potential temperature, and $S$ salinity. The thermal and haline expansion coefficients are $\alpha=-\rho_{o}^{-1} \partial \rho / \partial T$ and $\beta=\rho_{o}^{-1} \partial \rho / \partial S$. Only the experiments NONLIN, CABBEL, and CABBEL-A (see $\S 3$ e and Table 1) employ a nonlinear equation of state, which is implemented as a third-order polynomial fit in $\Theta$ and $S$ to the UNESCO formula for each depth level of the model, thus incorporating compressibility effects.

Besides potential temperature and salinity the model includes an additional passive tracer T3 that is used to trace the Mediterranean water inflow. ${ }^{1}$ Initial values for $\mathrm{T} 3$ are zero, and no-flux conditions apply at all boundaries including the surface; T3 is injected in the same manner as the Mediterranean salt anomaly (see §3e).

Initial conditions are derived from zonally averaged potential temperatures and salinities for the North Atlantic (excluding Hudson Bay and the Baltic) from Levitus (1982). The model is initially at rest. Surface momentum forcing is by a zonal wind stress that varies only in the meridional direction as in Cox and Bryan (1984). The wind stress crudely reflects the major zonal wind systems (Fig. 1). Restoring of the uppermost level

\footnotetext{
${ }^{1}$ Because we consider the spreading of MW in the Atlantic basin, we call the flow of warm and saline water from the Mediterranean an inflow into the Atlantic. This seems a more apropriate name than the more usual "Mediterranean outflow."
} 
TABLE 1. Description of the experiments discussed in the text. Individual experiments except the reference cases LIN and NONLIN employ a specific mechanism (marked with +) that is potentially important for MW spreading in the model. A source of MW is prescribed in the experiments denoted with "-A." All experiments except NONLIN, CABBEL, and CABBEL-A employ a linear equation of state. The last column contains the equivalent salt flux into the domain that is computed as the volume integral of tracer T3 over the whole model domain divided by 30 years, the period over which the source of T3 at the eastern boundary was switched on. T3 is a passive tracer that is treated exactly as the Mediterranean salinity anomaly. It is present in all experiments including the reference cases without a salinity anomaly. Thus, an equivalent salt flux can also be computed for these experiments to quantify the effect of the salt anomaly itself.

\begin{tabular}{|c|c|c|c|c|c|c|c|}
\hline Exp & Equation of state & $\begin{array}{c}\text { Diapycnal } \\
\text { diffusion }\end{array}$ & $\begin{array}{l}\text { Double } \\
\text { diffusion }\end{array}$ & $\begin{array}{c}\text { Isopycnal } \\
\text { diffusion }\end{array}$ & Inflow & $\begin{array}{l}\text { Salinity } \\
\text { anomaly }\end{array}$ & $\begin{array}{c}\text { Equivalent } \\
\text { salt flux } \\
\text { (Gt/yr) }\end{array}$ \\
\hline LIN & Linear & - & - & - & - & - & 0.56 \\
\hline DIFFUS & Linear & + & - & - & - & - & 2.37 \\
\hline DIFFUS-A & Linear & + & - & - & - & + & 2.37 \\
\hline DDMIX & Linear & + & + & - & - & - & 2.76 \\
\hline DDMIX-A & Linear & + & + & - & - & + & 2.75 \\
\hline ISOPYC & Linear & - & - & + & - & - & 14.27 \\
\hline ISOPYC-A & Linear & - & - & + & - & + & 14.27 \\
\hline CABBEL & Nonlinear & - & - & + & - & - & 14.11 \\
\hline CABBEL-A & Nonlinear & - & - & + & - & + & 13.51 \\
\hline INFLOW & Linear & - & - & - & + & - & 38.38 \\
\hline INFLOW-A & Linear & - & - & - & + & + & 38.38 \\
\hline INFLOW-FCT-A & Linear & - & - & - & + & + & 40.25 \\
\hline INFLOW-DD & Linear & + & + & - & + & - & 38.88 \\
\hline INFLOW-DD-A & Linear & + & + & - & + & + & 38.64 \\
\hline NONLIN & Nonlinear & - & - & - & - & - & 0.52 \\
\hline
\end{tabular}

temperatures and salinities toward zonally averaged climatological annual means (Fig. 1) for the Atlantic provides the thermohaline forcing of the model. The time constants for temperature and salinity restoring are both 50 days.

Momentum is redistributed by harmonic friction with coefficients $A_{M H}=4 \times 10^{4} \mathrm{~m}^{2} \mathrm{~s}^{-1}$ for the horizontal and $A_{M V}=10^{-3} \mathrm{~m}^{2} \mathrm{~s}^{-1}$ for the vertical direction. A noslip boundary condition applies at the northern and zonal boundaries, while we prescribe free-slip boundary conditions at the southern boundary and the bottom. The time step is $2 \mathrm{~h}$ for all prognostic variables. Advection of momentum is neglected because of the coarse resolution of the model.

For the numerical advection of tracers we use a firstorder accurate upwind scheme in most experiments. Gerdes et al. (1991) discuss the properties of the scheme in oceanic applications. Higher-order schemes like central differences suffer from unphysical extrema in the advected quantities that violate the second law of thermodynamics. These dispersive "ripples" must be suppressed with explicit diffusion, or other nonlinear algorithms (e.g., Farrow and Stevens 1995; Hecht et al. 1995). The upwind scheme, on the other hand, is free of dispersive ripples but includes implicit diffusion in the coordinate directions (and hence has a diapycnal component) that is proportional to the velocity component and the grid distance in each direction. The velocity dependence results in large diffusion in strong currents and regions of intense upwelling or downwelling, giving the scheme a rather bad reputation. This reputation is not fully deserved, however, as without explicit diffusion the grid Peclet number does not fall below 2, and the spreading of tracer anomalies is ad- vectively dominated. Implicit diffusion is especially small in weak currents like the interior of gyres and the model's eastern boundary region, that are of special concern in this study. At the depth of the MW, typical horizontal velocities in the interior are less than $0.1 \mathrm{~cm}$ $\mathrm{s}^{-1}$, yielding an implicit horizontal diffusivity smaller than $10^{2} \mathrm{~m}^{2} \mathrm{~s}^{-1}$. Outside of boundary layers the typical vertical diffusivity is less than $10^{-6} \mathrm{~m}^{2} \mathrm{~s}^{-1}$. The vertical diffusivity here also determines the diapycnal diffusion (see below, Fig. 3d). The implicit diffusivity is much smaller than the explicit diffusivities that we employ in some of the experiments. On the other hand, in models with explicit mixing and a central difference advection scheme where the mixing coefficient must be large enough to prevent numerical problems everywhere, the local Peclet number is $O\left(10^{-1}\right)$ in this quiescent region. The advectively dominated tracer balance of the upwind scheme is an important property that makes this scheme suitable for the investigation of different diffusion processes. The basic model does not include any explicit diffusion of tracers, while other experiments use different mixing parameterizations as will be described below.

\section{Experimental strategy, injection, and spreading mechanisms}

A list of experiments is given in Table 1 and the time integration is shown schematically in Fig. 2. Both the model with linear and with nonlinear equation of state are spun up from the initial conditions. We chose a spinup period of $50 \mathrm{yr}$ and an additional integration period of $30 \mathrm{yr}$ for each experiment. Individual experiments employ each a specific mechanism that is po- 


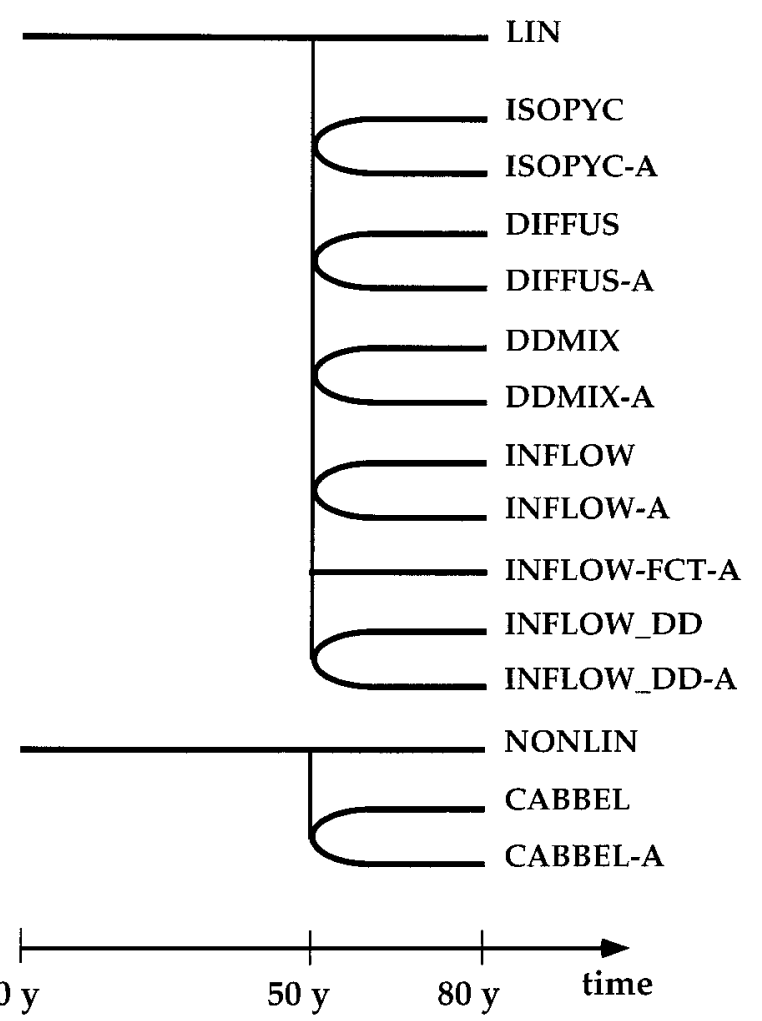

FIG. 2. Experiments and integration strategy. Reference experiments LIN and NONLIN (see text and Table 1 for a description of the experiments) are integrated for 80 years. Experiments exploring individual spreading mechanisms are initialized with the state of the corresponding reference experiment at year 50. An "-A" appended to the experiment name indicates the Mediterranean salt and temperature anomaly switched on.

tentially important for MW spreading in the model. A source of MW is prescribed during the duration of the experiment at one grid column at the eastern boundary. The procedure of specifying the source and the spreading mechanism are explained below.

\section{a. Integration period}

The spinup period of $50 \mathrm{yr}$ allows a dynamic adjustment, while the background model hydrography remains close to the initial condition. However, the Mediterranean temperature and salt signal contained in the initial fields dissipates during spinup. Preliminary experiments that were run to near-equilibrium $(1500 \mathrm{yr})$ yielded a final stratification that deviated strongly from the initial condition in that the static stability in the deep ocean was markedly reduced. This affects the efficiency of some of the mechanisms for large-scale spreading that we want to explore. Especially, vertical diffusion of tracers is partly compensated by vertical advection, which involves large vertical velocities when the stratification is weak. The associated vortex stretching of deep layers was thus unrealistically large in these initial experiments, resulting in an unrealistically large effect of vertical diffusion on the spreading of Mediterranean Water in the model. Therefore, we decided on the relatively short integration time that assures little deviation from the initial, more realistic stratification.

The individual experiments have to be relatively short for the same reason. We found that 30-yr experiments following the spinup of 50 years are sufficient to show the effect of different spreading mechanisms. This is no limitation of the experimental setup since, as pointed out earlier, any mechanism to explain the spreading of MW in the Atlantic must be efficient enough to establish the MW within a time period of a few decades.

\section{b. Reference runs}

Comparison of results from sensitivity experiments in a nonequilibrium state requires a careful strategy to avoid differences being attributed to physical factors, while they are at least partly due to differences in the adjustment process. Each experiment (denoted by a suffix "-A" to the experiment name) with the MW source present at the eastern boundary is therefore accompanied by a reference run where the source of MW is switched off. However, the same spreading mechanism as in the corresponding experiment is operating. Considering pairs of experiments with and without the MW anomaly serves another important purpose. It gives us the opportunity to distinguish between the effect of the spreading mechanism alone and the additional effect of the presence of the MW anomaly. The additional tracer T3 introduced above provides a convenient measure of these effects; T3 does not enter the equation of state and does not affect processes that depend on the salinity and temperature anomalies associated with MW. Differences in T3 between runs with and without an MW anomaly allow an estimate as to what degree the MW anomaly is an active tracer.

\section{c. Representation of MW inflow in the model}

For a large-scale model that does not include the processes in the vicinity of the inflow, the MW anomaly must be prescribed after the entrainment of ambient water into the plume is finished and the water mass has arrived at its final density level. The MW anomaly at the source should have a neutral density signal, and the salinity anomaly must be accompanied by a corresponding temperature anomaly. We want this property to be preserved during the whole duration of an experiment in spite of the evolving tracer fields. Therefore, temperature, salinity, and density at the injection location $37^{\circ} \mathrm{N}, 11^{\circ} \mathrm{W}$ (Fig. 1) are stored for each time step during the reference run corresponding to an individual experiment. During that experiment, these values are read in again and a salinity anomaly as shown in Fig. 1 is added. A temperature anomaly is determined by inversion of the equation of state such that the density of the new profile is identical to the reference values. The ad- 
ditional tracer T3 is set equal to the salinity anomaly. In most experiments, the new salinity and temperature profiles are prescribed at the injection column. Specification of MW at one grid column at the eastern boundary is justified by the finding of Price and O'Neill Baringer (1994) that inflow currents from marginal seas like the Mediterranean are in a nearly geostrophic balance over most of their path. The initial speed of an outflow is of little consequence, except as it affects the volume transport.

Another injection method is employed in the INFLOW experiments. Here a transport of MW is prescribed entering the model domain at one grid column at the eastern boundary. The actual flow into the North Atlantic has been estimated to be approximately $1 \mathrm{~Sv}$. As the MW plume flows into the Gulf of Cadiz, it entrains North Atlantic Central Water, increasing its volume transport by a factor of 3 (Käse and Zenk 1996). An exchange of $3 \mathrm{~Sv}$ across the eastern boundary, thus, is adequate for our large-scale model. The zonal inflow velocity is set constant to $2.493 \mathrm{~cm} \mathrm{~s}^{-1}$ between $900 \mathrm{~m}$ and $1441 \mathrm{~m}$ depth. The inflow is compensated by an outflow in the levels above $900 \mathrm{~m}$ such that the vertically integrated transport across the eastern boundary is zero. Outflow values for the tracers are predicted by the model. The temperatures and salinities of the inflow are taken from the end of the spinup to which anomalies have been added as described above. Since tracer values must be prescribed at inflow points, the procedure differs from that followed in the other experiments.

\section{d. Isopycnal mixing}

Spreading of the MW from the injection column is due to the large-scale advection and the (far less important) implicit diffusion of the advection scheme. In experiment ISOPYC-A and the corresponding reference experiment ISOPYC, isopycnal mixing is added as an additional spreading mechanism that is intended to mimic the action of the mesoscale eddy field on the largescale tracer distributions. The diffusion coefficients are assumed equal in the zonal and meridional direction and vary with depth according to

$$
A_{\text {Hiso }}=A_{d}+\left(A_{0}-A_{d}\right) \exp \left(-z / z_{e}\right),
$$

where $A_{0}=2.5 \times 10^{3} \mathrm{~m}^{2} \mathrm{~s}^{-1}, A_{d}=10^{3} \mathrm{~m}^{2} \mathrm{~s}^{-1}$, and the $e$-folding depth $z_{e}$ is $1000 \mathrm{~m}$. No explicit diapycnal mixing is employed. The isopycnal mixing tensor is implemented as in Gerdes et al. (1991) and differs from the Redi (1982) and Cox (1987) realization in the treatment of large vertical diffusive fluxes at steeply sloping isopycnals. To avoid violation of the CFL criterion in these regions, the isopycnal diffusion coefficient is reduced, but isopycnal orientation of the mixing tensor is not altered and no artificial diapycnal fluxes are introduced. Deviating from Gerdes et al. (1991), no horizontal boundary layer with horizontal mixing was implemented for these experiments.

\section{e. Diapycnal processes}

Experiments DIFFUS, DDMIX, INFLOW-DD, and CABBEL include different explicit diapycnal mixing processes. In DIFFUS explicit diapycnal diffusion is implemented with a constant diffusion coefficient of 0.5 $\times 10^{-4} \mathrm{~m}^{2} \mathrm{~s}^{-1}$. The DDMIX experiment uses different vertical diffusion coefficients for temperature and salinity. The passive tracer T3 is always treated like salinity. The implementation follows that of Gargett and Holloway (1992), with the ratio of the diffusion coefficients in DDMIX depending on the Turner angle. Following Ruddick (1983) the Turner angle is defined as the four-quadrant arctangent of $R_{\rho}=\alpha T_{z} / \beta S_{z}$, where $\alpha$ and $\beta$ are the thermal and haline expansion coefficients introduced above. (The DDMIX and INFLOW-DD experiments use a linear equation of state). Salt fingering can occur for stable temperature stratification and unstable salinity stratification, $T_{z}>0$ and $S_{z}>0$ in the range $1<R_{\rho}<\kappa_{T} / \kappa_{S}$, where $\kappa_{T}$ and $\kappa_{S}$ are the molecular diffusivities for temperature and salinity. Double diffusive layering can occur in regions with unstable temperature stratification and stable salinity stratification, $T_{z}<0$ and $S_{z}<0$, when $\kappa_{S} / \kappa_{T}<R_{\rho}<1$. Double diffusive mixing is most likely for density ratios close to the statically unstable limit given by $R_{\rho}=1$. The critical density ratio is set here to 2.8 for fingering. For $S_{z}>0$ and $R_{\rho}$ between 1 and 2.8 the turbulent diffusion coefficient for salinity (and tracer T3) is set to $10^{-4} \mathrm{~m}^{2}$ $\mathrm{s}^{-1}$, while the turbulent diffusion coefficient for temperature is kept at its standard value. For $S_{z}<0$ and $R_{\rho}$ between 1 and 0.36 the turbulent diffusion coefficient for temperature is doubled, while the coefficients for salinity and T3 remain at their standard value. To explore the potential effect of double diffusive mixing in the framework of the idealized model configuration and considering the uncertainties of the parameterizations, we decided on critical density ratios of 0.36 and 2.8 that delineate a relatively large domain unstable to double diffusive mixing. With the more common choice of 0.5 and 2.0 (Turner 1973; Schmitt 1979) double diffusive mixing in our model would be restricted to very small areas in the pycnocline and at the base of deep mixed layers. The same double diffusive parameterization is used in the INFLOW-DD experiments where we prescribe an inflow of $3 \mathrm{~Sv}$ across the eastern boundary as in the INFLOW experiment. This experiment serves as an example where a salt- and temperaturedependent mechanism is acting in the presence of a large-scale MW anomaly in the model interior.

Finally, in the experiments with the nonlinear equation of state (CABBEL/-A), as well as in the reference case NONLIN, the process of cabbeling (McDougall 1987 ) is enabled that is not present in the other experiments. Mixing of water masses with different $T-S$ properties and identical density results in a water mass that is denser than the parent water masses. This process is likely to be important where Subarctic Intermediate Wa- 
ter (SAIW) or Labrador Sea Water (LSW) mix with MW (Arhan et al. 1994). The increase in density due to the nonlinear equation of state can be interpreted as a diapycnal mixing that will spin up a circulation as in the cases with explicit diapycnal diffusion.

\section{Salt flux estimate}

Scaling arguments can be used to estimate the salt flux associated with different processes. The direct effect of vertical diffusion can be described by the salt flux estimate

$$
\mathrm{SF}_{v}^{\mathrm{diff}}=2 \rho_{o} A_{H V} \frac{\partial S^{\prime}}{\partial z} a^{2} \Delta \phi \Delta \lambda \cos (\phi)
$$

where $A_{H V}$ is the vertical diffusion coefficient, $a$ the earth's radius, and $\Delta \lambda$ and $\Delta \phi$ the grid distances in the horizontal direction. The factor 2 accounts for vertical fluxes above and below the MW anomaly. From the prescribed salt anomaly profile, we calculate $\left(\partial S^{\prime} / \partial z\right)_{\max }$ $=4.2 \times 10^{-6} \mathrm{~m}^{-1}$. A vertical diffusivity of $A_{H V}=0.5$ $\times 10^{-4} \mathrm{~m}^{-2} \mathrm{~s}^{-1}$ results in a flux of $0.5 \mathrm{Gt} / \mathrm{yr}$ that is two orders of magnitude smaller than the observed flux from the Mediterranean into the Atlantic.

However, diapycnal mixing affects the vorticity balance of individual density layers. The linear vorticity balance vertically integrated over a layer defined by the density surfaces $z=h^{n}$ and $z=h^{n-1}$ is

$$
\beta \int_{-h^{n}}^{-h^{n-1}} v d z=f\left[w\left(-h^{n-1}\right)-w\left(-h^{n}\right)\right],
$$

where the vertical velocities are given by

$$
w\left(-h^{n}\right)=-h_{t}^{n}-\mathbf{u}^{n} \cdot \nabla h^{n}+w_{s}\left(-h^{n}\right) .
$$

The meridional transport consists of a source-sink part and a part driven by vortex stretching associated with local thickness changes and diapycnal velocities $w_{s}\left(-h^{n}\right)$. Assuming an advective-diffusive balance in the vertical we estimate typical diapycnal velocities at the depth of the MW anomaly as $w_{s}=5 \times 10^{-8} \mathrm{~m} \mathrm{~s}^{-1}$, which we also take as the magnitude of the vertical velocity difference $\Delta w_{s}$. This yields a salt flux through the grid cell where the MW is inserted of

$$
\mathrm{SF}^{\mathrm{adv}}=\rho_{o} S^{\prime} \frac{f \Delta w_{s}}{\beta} a \Delta \lambda \cos (\phi) \approx 1.4 \mathrm{Gt} / \mathrm{yr} .
$$

The salt flux due to isopycnal diffusion through a closed surface encircling the source of MW can be estimated as

$$
\begin{aligned}
\mathrm{SF}^{\text {iso }}= & \rho_{o} A_{\mathrm{iso}} \nabla S^{\prime} \pi h a\left(\Delta \phi^{2}+\Delta \lambda^{2} \cos ^{2} \phi\right)^{1 / 2} \\
& \approx 14.9 \mathrm{Gt} / \mathrm{yr},
\end{aligned}
$$

where an isopycnal mixing coefficient of $A_{\text {iso }}=1.5 \times$ $10^{3} \mathrm{~m}^{2} \mathrm{~s}^{-1}$ and a vertical scale $h=500 \mathrm{~m}$ have been used. The salinity gradient has been estimated using a length scale of $2000 \mathrm{~km}$. This simple analysis shows that all of the above processes are insufficient to establish and maintain the MW anomaly in the model and that all fluxes by interior processes are much smaller than the flux across the eastern boundary in the INFLOW experiments, which has been chosen as $46.4 \mathrm{Gt} /$ yr according to observed transports between the Mediterranean and the Atlantic.

\section{Results}

\section{a. Reference case: Hydrography and currents near the eastern boundary}

The experiment LIN serves as a reference for the subsequent experiments and is therefore described in detail. In Fig. 3 we show salinity, meridional velocity component, density, and diapycnal diffusivity for a section along $37^{\circ} \mathrm{N}$, the latitude of the MW source in the model. The results for the reference case with the full equation of state (NONLIN) are very similar and not shown here.

The large-scale salinity distribution (Fig. 3a) is dominated by the high salinities of the subtropical gyre. In the eastern part of the gyre two fresher waters introduce pronounced salinity minima in the water column. Low salinities at around 100-m depth are due to water that subducts from the deeper mixed layers north of the section and is advected with the general southward circulation. Closer to the eastern boundary a wedge of relatively fresh water reaches down to at least 1000-m depth. The source of this water is the eastern boundary north of $42^{\circ} \mathrm{N}$. There, strong downwelling combined with convective mixing brings relatively fresh water from the surface to depths of more than $500 \mathrm{~m}$. The cause of the downwelling is the convergence at the boundary of the geostrophic currents associated with the wind-forced surface tilt (more precisely the surface pressure gradients at the rigid lid) and the meridional density gradient enforced by the surface thermohaline boundary condition.

The meridional velocity section (Fig. 3b) contains the southward Ekman transport in the uppermost model box and the more sluggish southward recirculation of the subtropical gyre. In the eastern half of the domain the southward recirculation is intensified in a band sloping upward from around $1000-\mathrm{m}$ depth at $33^{\circ}$ model longitude to around $300 \mathrm{~m}$ at the eastern boundary. Below and east of this band lies a northward current with maximum velocities of slightly above $0.2 \mathrm{~cm} \mathrm{~s}^{-1}$. Currents are extremely weak at greater depths. The weakness of the large-scale circulation at the MW level is the cause for weak interior penetration of MW in many models of the North Atlantic general circulation.

The deep reaching freshwater identified above near the eastern boundary is weakly stratified and appears in the density section (Fig. 3c) as a vertical spreading of density surfaces. This water resembles subpolar mode water found in the eastern North Atlantic (McCartney 

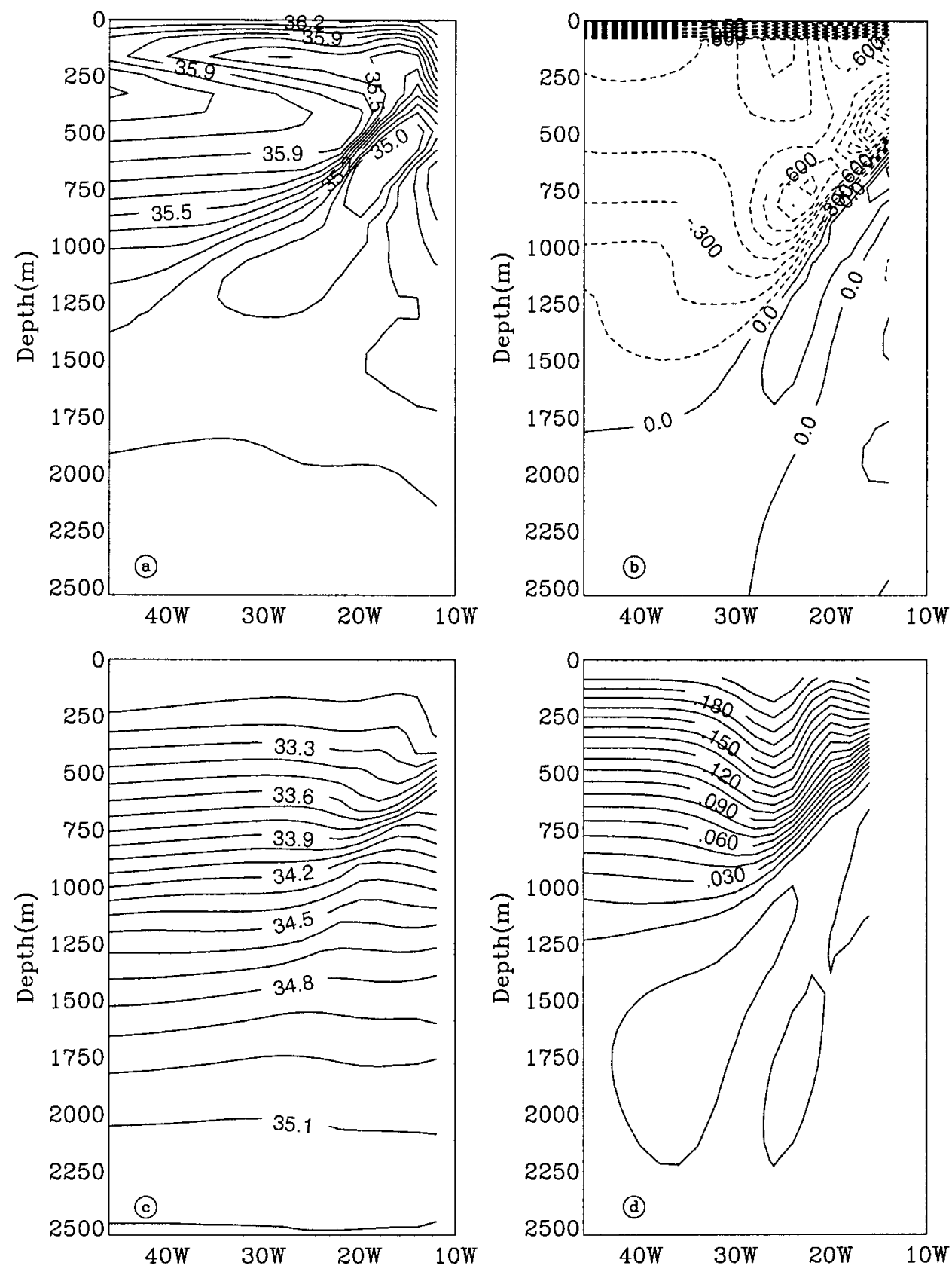

FIG. 3. Sections along $37^{\circ} \mathrm{N}$ at the end of the reference experiment LIN: (a) salinity; (b) meridional velocity component, positive for northward flow (contour interval: $0.2 \mathrm{~cm} \mathrm{~s}^{-1}$ ); (c) potential density; and (d) implicit diapycnal diffusivity $A_{v}^{\text {impl }}+A_{H}^{\text {impl }}\left(\nabla \rho / \rho_{z}\right)^{2}$, where the $A^{\text {impl }}$ denote the implicit diffusivities in the vertical and horizontal directions due to the upstream advection scheme (contour interval $0.01 \mathrm{~cm}^{2} \mathrm{~s}^{-1}$ ). For clarity, the easternmost grid column was not contoured.

and Talley 1982). Because of the depression of density surfaces, the core of the mode water is associated with low pressure. A low pressure trough stretches out along the eastern and most of the southern rim of the subtropical gyre. The cyclonic circulation around the trough intensifies the southward recirculation of the subtropical gyre on the western side of the mode water, while a northward current is present near the eastern boundary.
At $37^{\circ} \mathrm{N}$ the cyclonic circulation around the mode water core can be observed at depths between 450 and 800 $\mathrm{m}$ (Fig. 3b). In the upper parts of the water column the mode water is still close to the eastern boundary and the low pressure is situated near the coast (note the deflection of the density surface $\sigma_{1}=33.2$ ). A northward current is not present at these depths.

Below the mode water the permanent pycnocline 

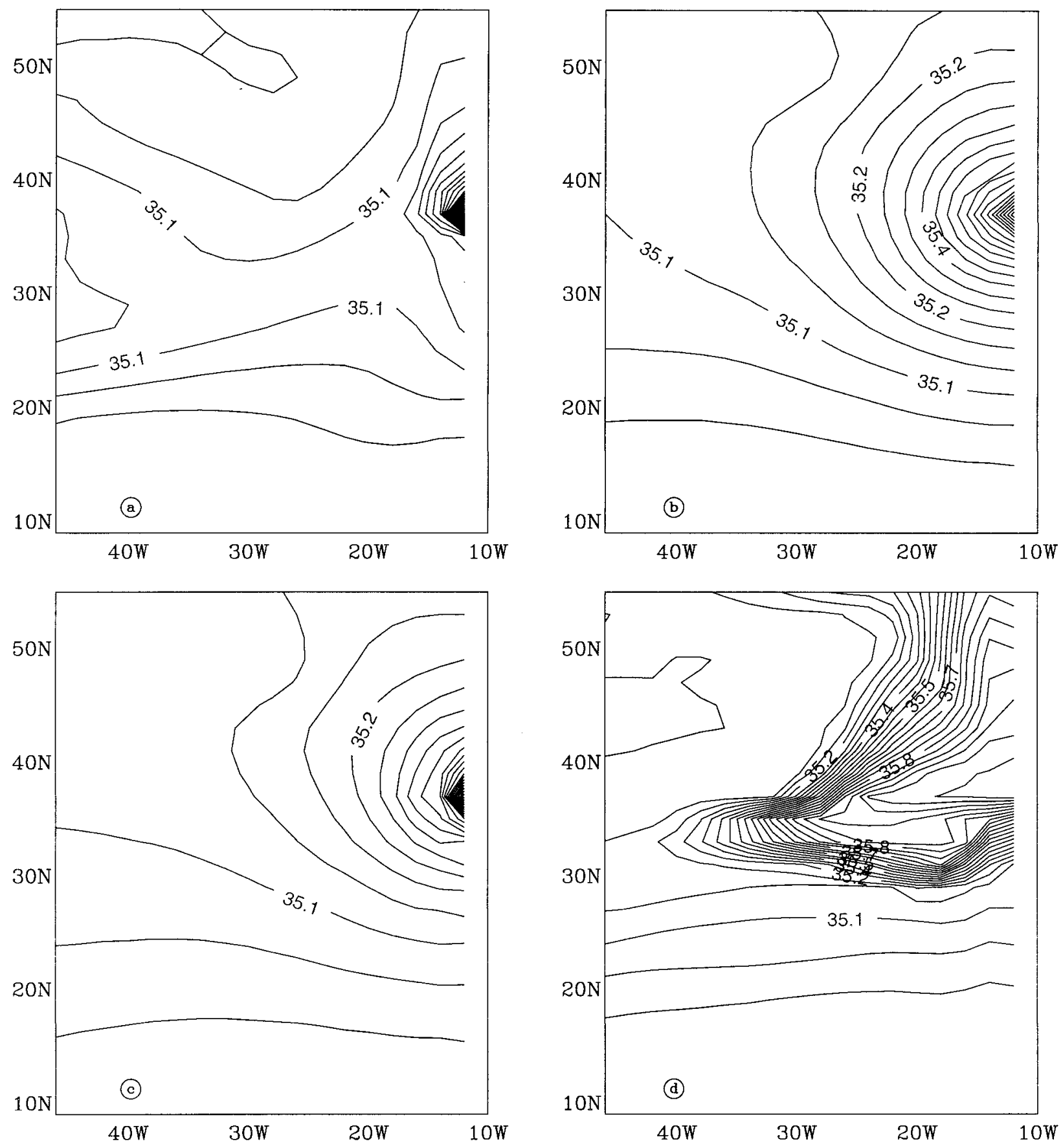

FIG. 4. Salinity at 1180-m depth for experiments (a) DIFFUS-A, (b) ISOPYC-A, (c) CABBEL-A, (d) INFLOW-A, (e) INFLOW-FCT-A, and (f) INFLOW-DD-A.

slopes upward toward the eastern boundary. Between the pycnocline and the eastern boundary the density surfaces are essentially flat, as can be expected for the eastern shadow zone of the subtropical gyre. Models of similar resolution as LIN usually do not exhibit such a detailed eastern boundary current regime. The complex structure in LIN is possible because of the low implicit diffusion of the upstream scheme used for the advection of temperature and salinity. The implicit diffusivities in the horizontal and vertical directions have been diagnosed and combined in Fig. 3d to an estimate of implicit diapycnal diffusion at the latitude of the MW inflow. Maximum values reach $0.2 \mathrm{~cm}^{2} \mathrm{~s}^{-1}$ near the surface, while at the depth of the MW extremely small values of around $0.01 \mathrm{~cm}^{2} \mathrm{~s}^{-1}$ prevail. Implicit diffusivities are larger in an eastern boundary layer one grid column 

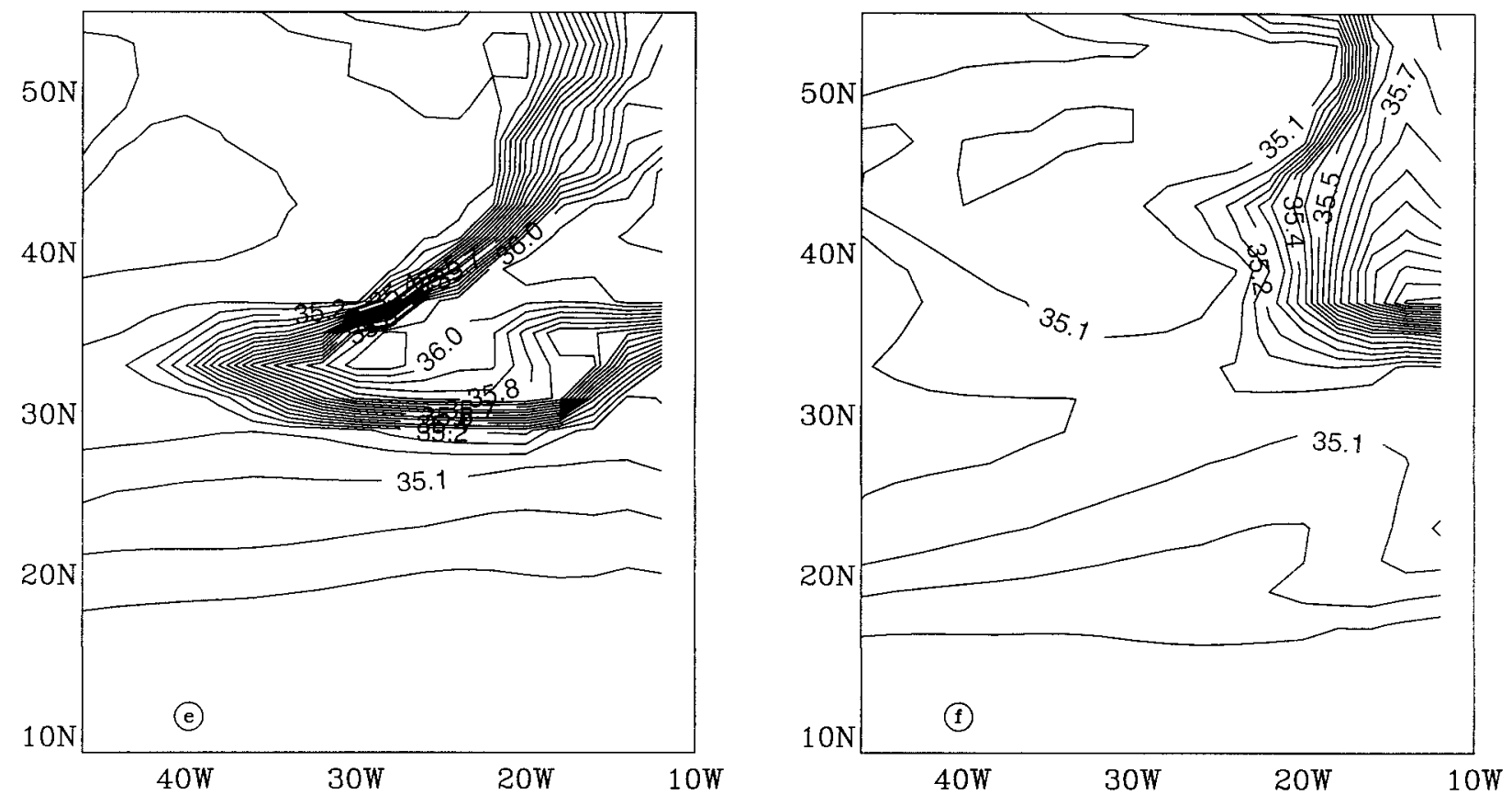

FIG. 4. (Continued)

wide (not shown) where the convergent near-surface flow forces strong downwelling.

\section{b. Mediterranean water: Overview}

The central results of the comparison are summarized in Fig. 4 and Table 1. The figure shows salinity distributions at 1180-m depth for six experiments that contain the MW anomaly. It represents a wide range of solutions from MW anomalies restricted to the immediate vicinity of the injection point (DIFFUS-A) to pronounced MW tongues that stretch $30^{\circ}$ in the zonal direction and reach the northern boundary at the eastern side of the domain (INFLOW-A, INFLOW-FCT-A). Somewhat in between are the results for isopycnal mixing (ISOPYC-A, CABBEL-A) and with inflow and diapycnal mixing (INFLOW-DD-A).

In the last column of Table 1 we list the flux of tracer T3 into the model domain for all experiments and reference runs. Here T3 is treated exactly as the salinity anomaly that is added onto the salinity profile taken from each reference run. Therefore, the volume integral of T3 can be interpreted as the volume of MW that has been formed during the 30 years integration time of the experiment. An average tracer flux into the model domain can be calculated by dividing the volume integral by the integration period. For better comparison with observations, this can be interpreted as an equivalent salt flux that is needed to form the new MW during an experiment.

There are actually no significant sinks of salt in the Mediterranean and therefore no significant net salt trans- port takes place through the Strait of Gibraltar. The rigid-lid model, on the other hand, cannot accommodate a volume transport through the surface, and net evaporation over the Mediterranean must be replaced by an equivalent salt flux through the surface. Correspondingly, the model requires zero net volume flux and nonvanishing salt transport through the eastern boundary.

Since T3 has no dynamical effect, it can be inserted in the reference runs as well as in the sensitivity experiments. This allows one to evaluate the effectiveness of different injection and spreading mechanisms with and without the Mediterranean salt and temperature anomaly present. Table 1 thus contains the results of the tracer analysis interpreted in the sense of a salt anomaly for both the reference runs and the actual experiments. Irrespective of the presence of a salinity anomaly, we will in the following address the $\mathrm{T} 3$ component of the water as MW.

The results listed in Table 1 corroborate the impression gained from the salt distributions of Fig. 4. Simple insertion of a MW anomaly in the reference runs LIN and NONLIN yields very small MW volumes after 30 years of integration because large-scale advection and implicit diffusion of the advection scheme are the only spreading mechanisms. Velocities (and thus implicit mixing) are extremely small near the eastern boundary at the injection latitude (Fig. 3b). The tracer T3 prescribed at the grid column centred at $37^{\circ} \mathrm{N}, 11^{\circ} \mathrm{W}$ thus basically remains at the injection point, and the volume of newly formed MW is the smallest of all experiments. The results for diapycnal and isopycnal diffusion are in good agreement with the flux estimates of section 4 . 


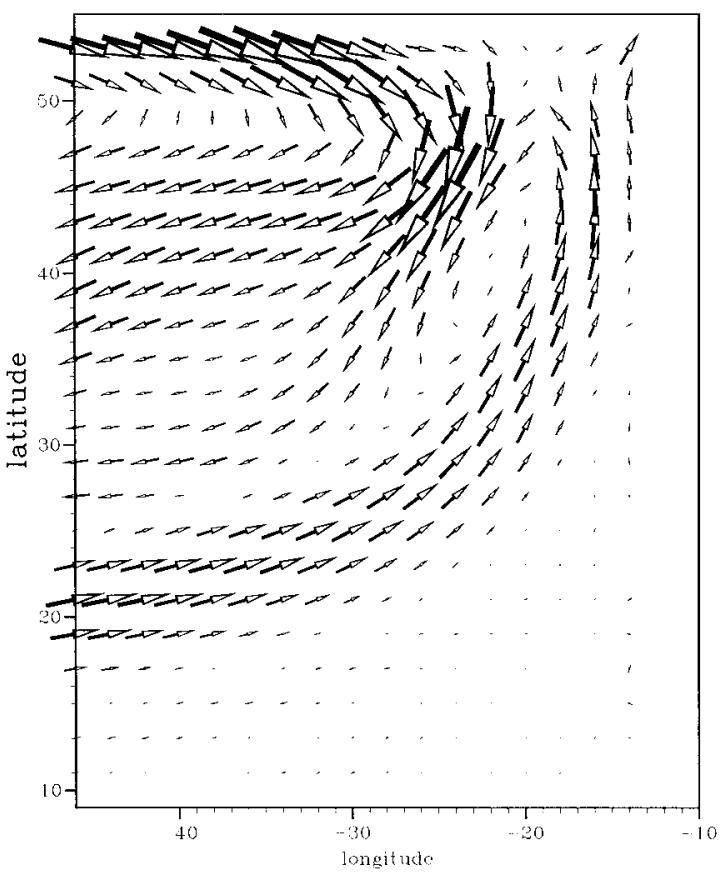

FIG. 5. Velocity difference between experiments DIFFUS-A and LIN at $1180-m$ depth. The largest vector length corresponds to a velocity of $0.45 \mathrm{~cm} \mathrm{~s}^{-1}$.

Only the INFLOW experiments exhibit a salt flux that is close to the observed Mediterranean-Atlantic exchange. The salt fluxes are smaller than the prescribed $46.38 \mathrm{Gt} / \mathrm{yr}$ because a small part of the MW leaves the model domain in the upper $900 \mathrm{~m}$ of the water column. In the following we will examine the individual processes in more detail.

\section{c. Diapycnal diffusion}

Vertical diffusion with either constant coefficients (DIFFUS) or a parameterization of double diffusion (DDMIX) results in an increase of the MW volume compared to the reference runs. This is an indirect effect of vertical diffusion and mainly due to changes in the large-scale circulation. Vortex stretching caused by upward vertical velocities above the MW depth combined with downward velocities deeper in the water column forces a cyclonic circulation at the MW depth (Fig. 5). The strength of that circulation, especially of the northward flow near the eastern boundary, increases with vertical mixing. In a stationary state with no horizontal fluxes the vertical velocity would be given by a onedimensional advective-diffusive balance,

$$
w_{a d}=\kappa \frac{\rho_{z z}}{\rho_{z}} .
$$

Comparison of this quantity and the actual vertical velocity at 1000-m depth for the DIFFUS experiment in
Fig. 6 indicates that diapycnal diffusion is indeed a controlling process for the vertical motion at the eastern and southern margin of the subtropical gyre. Compared to LIN (without explicit diapycnal diffusion) the area of upwelling at 1000-m depth increases and shifts to the south and east. The change in vertical velocity is linked to positive curvature of the density profile in the region of mode water above the MW level and negative curvature in deeper levels. The model's cyclonic circulation formed by the subtropical recirculation and a diffusively driven eastward current that turns northward near the eastern boundary (Fig. 5) is consistent with the dynamic height constructed by Reid (1994) for the MW level (see also Fukumori 1991).

The volume of MW increases further due to double diffusion, mainly because the overall diapycnal mixing is higher. A small difference in MW volume arises between DDMIX and DDMIX-A due to the presence of the MW anomaly, which changes the local salinity and temperature gradients. However, the effect of double diffusion is very limited in the model. Double diffusion occurs in the pycnocline of the subtropical gyre and in the immediate vicinity of the eastern boundary where the MW anomaly is present. The vertical salinity stratification is too weak compared to the temperature stratification as to cause double diffusion in most of the interior model domain.

\section{d. Isopycnal diffusion}

Isopycnal mixing in ISOPYC-A is more efficient in distributing MW from the source into the interior. The equivalent salt flux is roughly one-third of that estimated for the Atlantic although the diffusion coefficient of around $1.5 \times 10^{3} \mathrm{~m}^{2} \mathrm{~s}^{-1}$ at the MW level seems already higher than justified for the relatively quiet eastern subtropical North Atlantic. Isopycnal mixing does not affect the density, the current field is identical to LIN shown above (Fig. 3b). The velocity at the depth of the Mediterranean inflow is thus very small and the tracer balance is dominated by the rather large diffusion. Consequently, the structure of the salinity field at $1180-\mathrm{m}$ depth (Fig. 4b) is very isotropic and does not resemble the characteristic pattern of the MW distribution. Only near the northern boundary, in a region of strong westward currents, an advective influence is noticeable.

\section{e. Nonlinear equation of state}

The result for isopycnal mixing and the full equation of state (CABBEL) is very similar, indicating that nonlinearities in the equation of state are of minor importance in the eastern and interior parts of the model domain. However, the introduction in experiment CABBEL-A of a water that is very different in its properties from the ambient water results in a sizeable effect on the MW volume. The much fresher and colder surrounding water is influenced by the mode water formed 

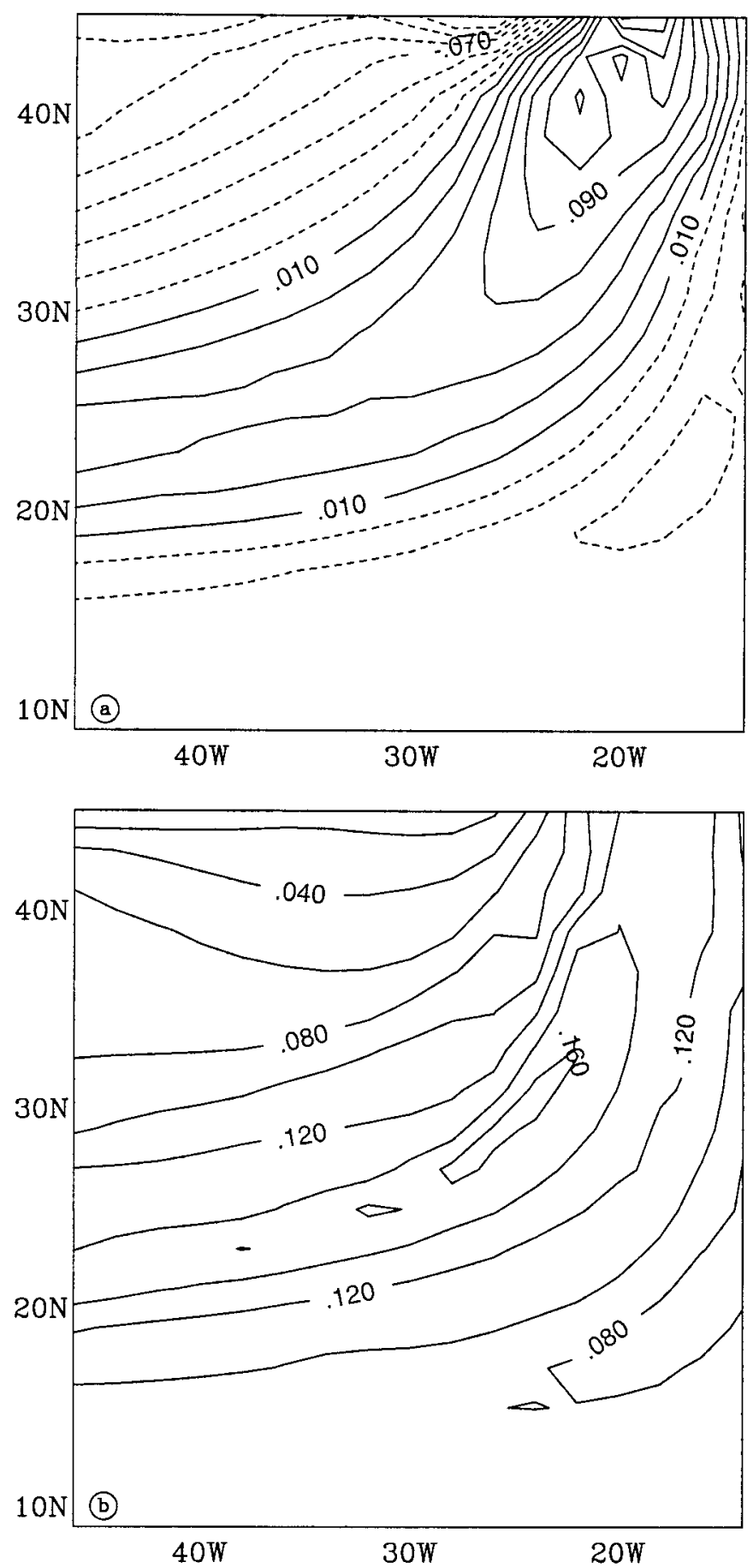

FIG. 6. (a) Vertical velocity and (b) diffusively compensated vertical velocity $w_{\text {ad }}=\kappa\left(\rho_{z z} / \rho_{z}\right)$ at 1000 -m depth for the DIFFUS experiment. Contour interval is $0.02 \times 10^{-4} \mathrm{~cm} \mathrm{~s}^{-1}$. For clarity, the eastern boundary layer (one grid box) has not been plotted.

in the northeast corner of the model domain (see above). Mixing of MW and this surrounding water results in a density increase of $0.06 \mathrm{~kg} \mathrm{~m}^{-3}$ at $1180-\mathrm{m}$ depth. The density signal propagates northward along the eastern boundary due to coastal waves and self advection of the density anomaly. The associated velocity anomaly consists of a cyclonic cell with northward currents at the eastern boundary and eastward currents at the latitude of MW source above the maximum MW anomaly (Fig. 7a). Below, the anomalous circulation is reversed (Fig. 

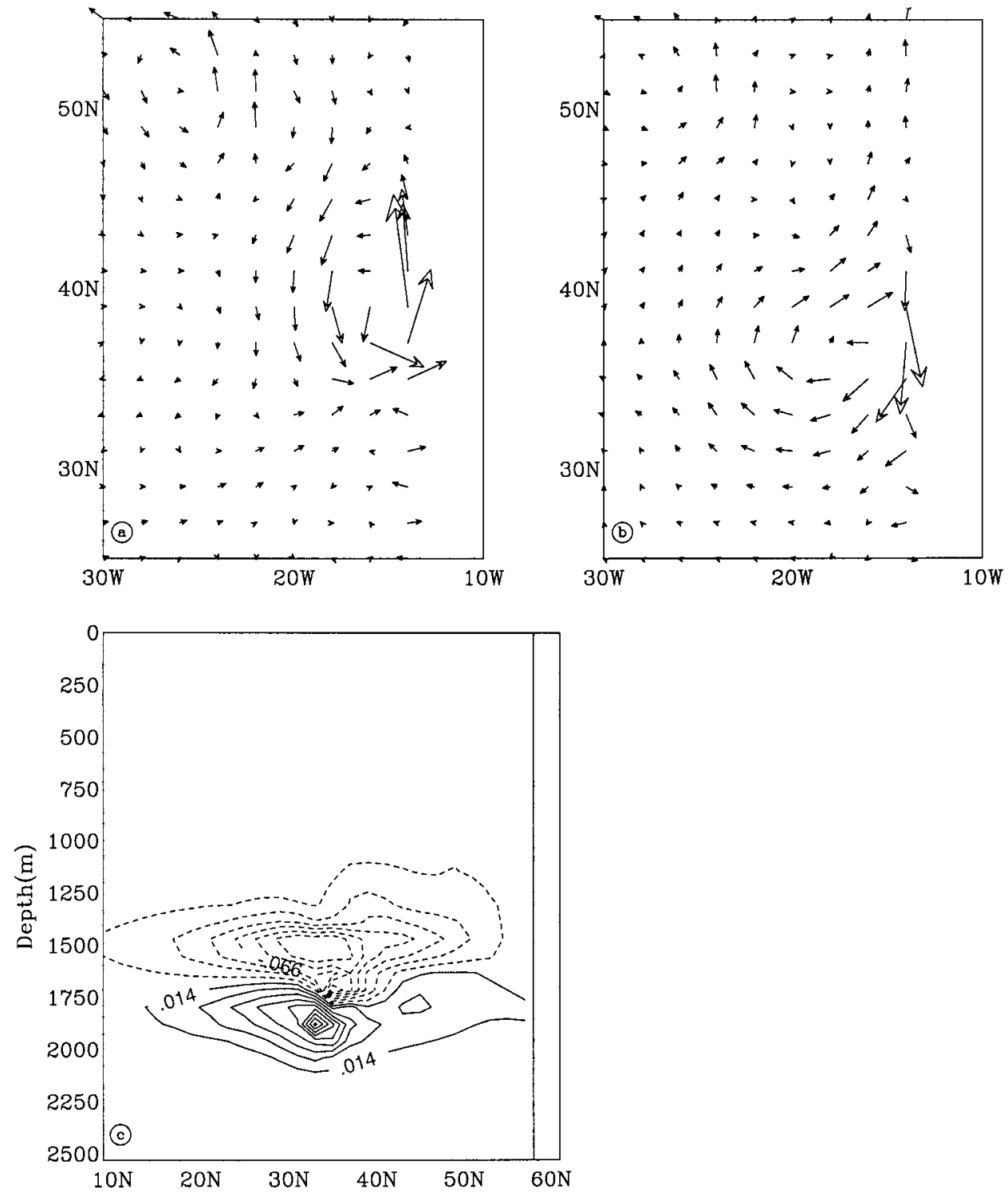

FIG. 7. (a) velocity difference at $1000-\mathrm{m}$ depth and (b) velocity difference at $1400-\mathrm{m}$ depth between CABBEL-A and CABBEL experiments. The maximum velocities are 0.59 and $0.43 \mathrm{~cm} \mathrm{~s}^{-1}$, respectively. (c) Tracer T3 difference between CABBEL-A and CABBEL for a meridional section at the eastern boundary. Contour interval: 0.02 .

7b). Maximum horizontal velocities are around $0.5 \mathrm{~cm}$ $\mathrm{s}^{-1}$. With this velocity scale and an isopycnal mixing with $A_{\text {Hiso }}(1200 \mathrm{~m}) \approx 1.5 \times 10^{3} \mathrm{~m}^{2} \mathrm{~s}^{-1}$ the grid Peclet number is only 0.7 , indicating that the tracer balance on a density surface is still dominated by diffusion. The horizontal salinity distribution at the MW level (Fig. 4c) thus hardly differs from the case with a linear equation of state and also lacks the typical pattern of the observed MW distribution. Effects of the nonlinear equation of state are more noticeable in the vertical direction where only the small implicit diffusion of the advection scheme acts on the tracer fields. At the location of the MW source the anomalous vertical velocity is down- ward, resulting in a vertical displacement of the MW anomaly in CABBEL-A compared to the reference experiment CABBEL. Differences in T3 at the eastern boundary illustrate the vertical shift of the MW (Fig. 7c). While the differences at the injection latitude are mainly due to vertical advection, the meridional spreading of the signal is mainly due to isopycnal diffusion.

Alternating zonal currents south of the injection latitude (Fig. 7a) hint at a numerical problem with the pointwise introduction of the anomaly. This numerical noise appears in all experiments where the density field is affected by the MW anomaly. It has negligible influence on the large-scale distributions because it is con- 
fined to the eastern boundary and remains on a small scale during the whole integration.

\section{f. Inflow}

In the INFLOW-A experiment realistic salt and volume fluxes are prescribed to enter the model domain at depth between 900 and $1440 \mathrm{~m}$. The salinity distribution at 1180-m depth (Fig. 4d) after 30 years of integration shows that the MW penetrates $30^{\circ}$ of longitude into the interior. The MW does not spread south of $30^{\circ} \mathrm{N}$ in this experiment and extends all along the eastern boundary and into the northern boundary current regime.

Although the MW at the eastern boundary has no anomalous density signal, the mass flux of $3 \mathrm{~Sv}$ induces a significant change in the density field near the injection point by pushing apart the density surfaces above and below the inflow. A major effect of the inflow is thus the change in the potential vorticity as shown in Fig. 8 for the potential density surface 27.5 (note that the equation of state does not contain compressibility effects in the INFLOW experiment). Compared to the reference case LIN the potential vorticity in the MW tongue is much lower and more uniform.

The velocity field at the MW level (Fig. 9) contains a zonal current at the inflow latitude that connects with the deep westward flow of the subtropical gyre in the western parts of the basin. However, most of the MW turns in a northeastward direction at around $45^{\circ}$ model longitude.

Examination of the spinup processes in response to the MW inflow is useful to explain the quasi-steady state of Fig. 9. Animation of the meridional velocity field at $1180 \mathrm{~m}$ revealed the development of a northward eastern boundary current within the first few months after switching on the MW inflow. The fast northward propagation of this signal can be seen in the Hovmöller diagram of Fig. 10a. We can distinguish two vertical modes of Kelvin waves with phase speeds of 5.9 and $1.3 \mathrm{~cm} \mathrm{~s}^{-1}$. These relatively low-phase speeds are due to the heavy distortion of Kelvin waves in a numerical model that does not resolve the first internal Rossby radius (Hsieh et al. 1983), which is $30 \mathrm{~km}$ at this latitude in the model. However, the propagation speed is much greater than the mean meridional velocity that can be seen in the tracer T3. Due to the Kelvin wave adjustment to the inflow a boundary layer develops during the first two years along the whole eastern boundary north of the injection latitude. The boundary layer broadens during further stages of the adjustment, resulting in the maximum northward velocity found $10^{\circ}-20^{\circ}$ of longitude offshore at the end of the experiment (Fig. 9). At the injection latitude we see westward propagating signals in the meridional velocity (Fig. 10b) with phase speeds of 0.57 and $0.12 \mathrm{~cm} \mathrm{~s}^{-1}$. These speeds are not distinguishable from the mean advection; however, the character of the adjustment suggests the radiation of Rossby waves from the eastern boundary layer. Rossby
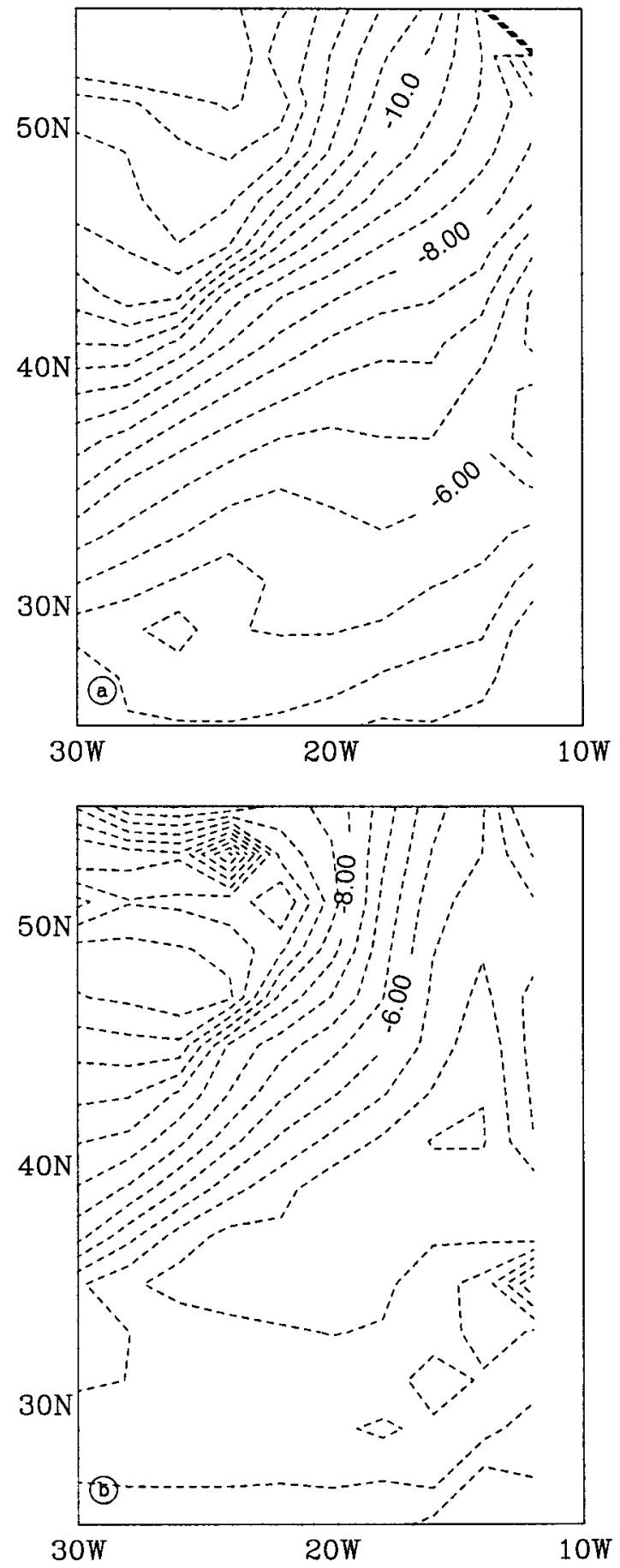

FIG. 8. Potential vorticity distribution on the density surface 27.5 for (a) INFLOW-A and (b) LIN. Contour interval: $0.5 \times 10^{-10} \mathrm{~cm}^{-1}$ $\mathrm{s}^{-1}$.

waves generated by the upwelling within a single column of $200-\mathrm{km}$ side length at the MW inflow have large meridional wavenumbers. This would imply a southwestward energy transfer. The northward expansion of 


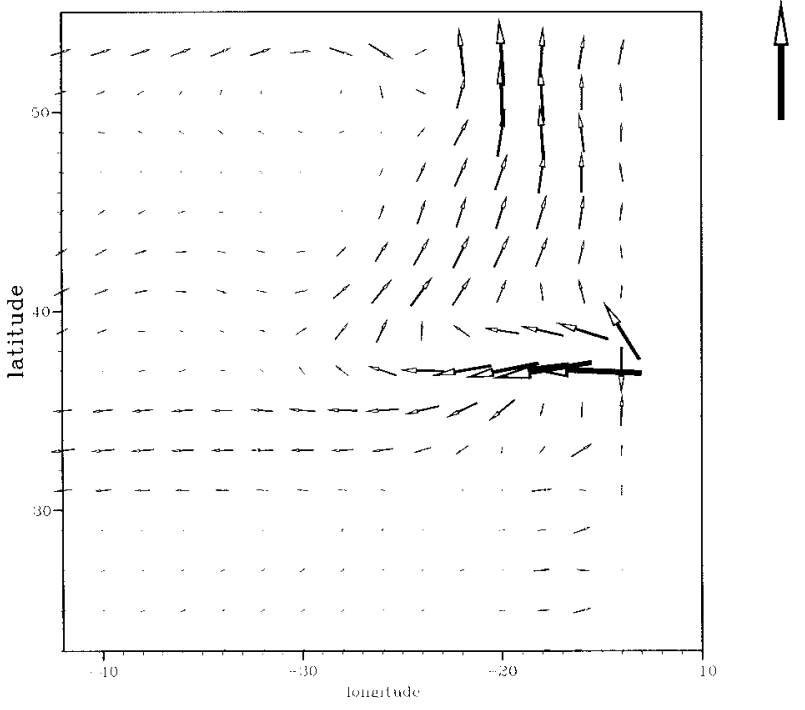

FIG. 9. Velocity at 1180-m depth for the INFLOW-A experiment. The maximum velocity is $1.07 \mathrm{~cm} \mathrm{~s}^{-1}$. The velocity field has been smoothed south of the inflow position to suppress numerical noise.

the MW upwelling reduces the effective meridional wavenumber and the energy transmission becomes zonal in the course of the integration. Rossby wave propagation is halted by the deep-reaching eastward current between the subtropical and subpolar gyres in higher latitudes.

\section{g. Influence of the advection scheme}

The implicit diffusion of the upstream scheme is negligible in the middepth eastern basin of the model (Fig. $3 \mathrm{~d})$ because velocities are very small. With prescribed horizontal velocities of $2.5 \mathrm{~cm} \mathrm{~s}^{-1}$ at the eastern boundary in the INFLOW experiments this might no longer be true. Therefore, in experiment INFLOW-FCT-A we have repeated the INFLOW-A experiment with the flux corrected transport (FCT) scheme (Zalesak 1979; Gerdes et al. 1991). Using antidiffusive fluxes, the flux difference between a central difference scheme and the upstream scheme, FCT minimizes implicit diffusion under the constraint that from one time step to the next, no new extrema are created by advection.

The salinity distribution at $1180 \mathrm{~m}$ (Fig. 4e) shows a similar zonal extent of the MW tongue as in INFLOW (Fig. 4d). The area of homogeneously high salinity is larger with the FCT scheme and the front between the MW and the interior is tighter. Overall there is, however, no qualitative difference between the results.

\section{h. Double diffusion in the presence of a large-scale MW anomaly}

Finally, in INFLOW-DD and INFLOW-DD-A, we combine the prescribed inflow of $3 \mathrm{~Sv}$ of $\mathrm{MW}$ at the eastern boundary with the double diffusive mixing parameterization described above. To reduce the influence of implicit diffusion, we use the FCT advection scheme for these experiments. Double diffusive mixing associated with a MW tongue that reaches far into the interior redistributes heat, salt, and tracer more effectively than in the case of an anomaly limited to the eastern boundary as in the DDMIX experiments. To illustrate the MW-dependent effect of double diffusion we show in Fig. 11 tracer distributions in 1180-m depth for INFLOW-FCT, INFLOW-DD, and INFLOW-DD-A. Comparison of INFLOW-FCT and INFLOW-DD shows that explicit diapycnal mixing limits the zonal extend of the tracer signal independently of the presence of the MW anomaly (Figs. 11a and 11b). This effect is due to the decay of the baroclinic Rossby waves by diapycnal diffusion as discussed by Tziperman (1987) and more recently by Spall (1999, manuscript submitted to J. Phys. Oceanogr.). Damping of westward propagating Rossby waves results in a steady state where less of the prescribed transport is carried by zonal currents and more is channeled into meridional currents closer to the eastern boundary. The presence of the MW anomaly in INFLOW-DD-A (Fig. 11c) strengthens this effect and limits the zonal extent of the anomaly further.

\section{Discussion and conclusions}

We have presented results from a series of numerical experiments designed to quantify the effect of different processes on the spreading of MW. The common technique of restoring temperature and salinity to an observed distribution near the Mediterranean inflow fails to produce an adequate Mediterranean Water mass because the eastern boundary region near the MW outflow is rather quiescent in the models. Large-scale circulation and mixing in our standard case (LIN) are not able to spread the MW signal much beyond the injection point. Velocities are very small at the depth of the MW anomaly and near the eastern boundary. The reasons for the small velocities are twofold: The wind-driven gyre does not reach down to $800 \mathrm{~m}$ or below near the eastern boundary; therefore there is no subtropical recirculation at the level of the MW. Thermohaline-driven flow is to a large degree restricted to western and northern boundary currents near the surface and at depth [compare the circulation pattern found by Cox and Bryan (1984) in a similar model configuration]. This might of course be different in a more realistic model. However, we neither see significant currents in the Atlantic model of Gerdes and Köberle (1995) nor do we see coherent mean currents in high-resolution models of the Atlantic circulation (Beckmann et al. 1994; Klinck 1995) at the MW level that could carry MW far into the interior of the basin.

Diapycnal processes like double diffusion and cabbeling have been suggested as processes responsible for the large-scale distribution of MW in the Atlantic (e.g., 

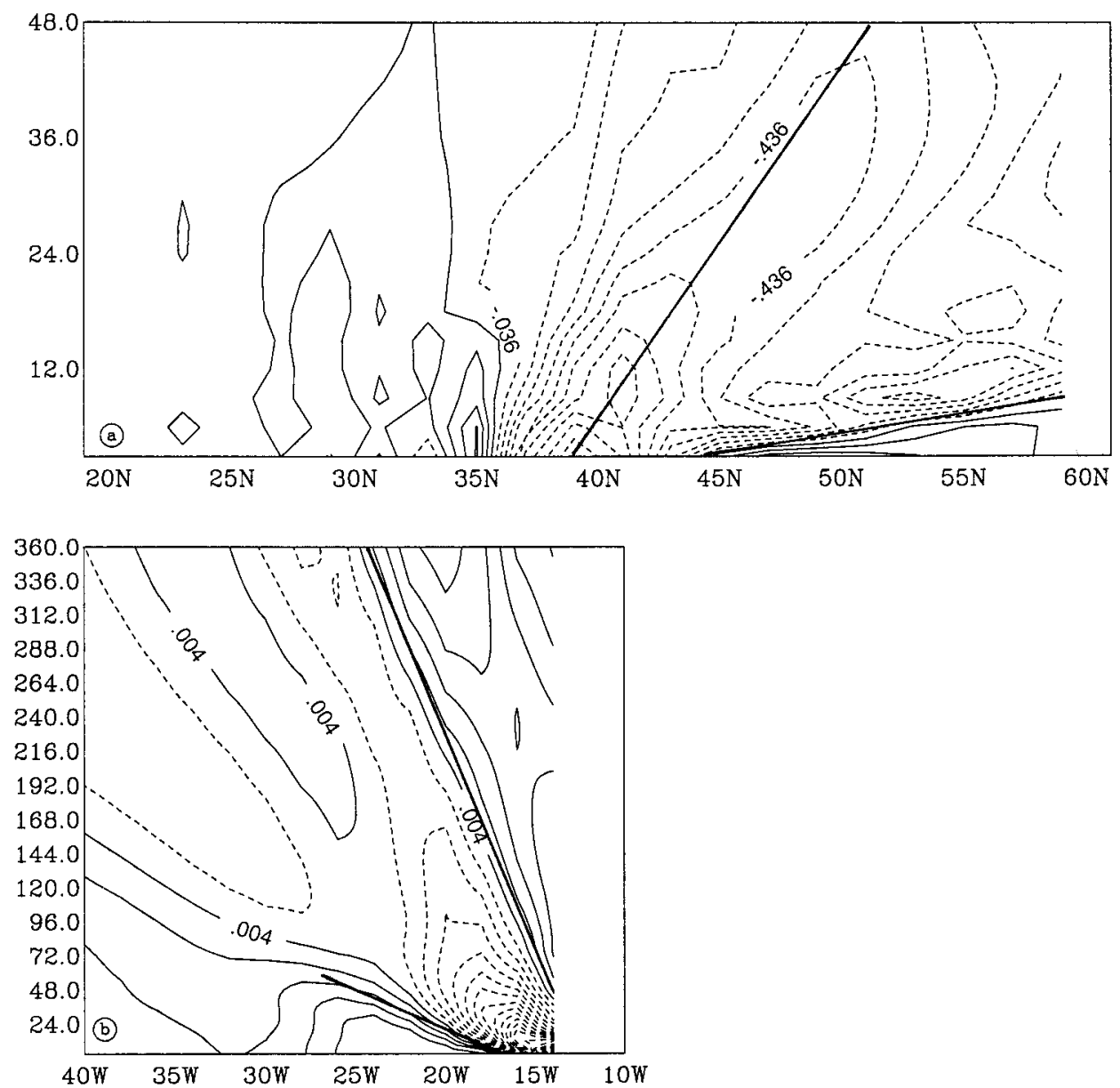

FIG. 10. (a) Hovmöller diagram of the meridional velocity component in experiment INFLOW-A at 1180$\mathrm{m}$ depth one grid point off the eastern boundary. The straight lines indicate northward propagation with 1.9 and $5.9 \mathrm{~cm} \mathrm{~s}^{-1}$, respectively. (b) Hovmöller diagram of the meridional velocity component at 1180-m depth at $35^{\circ} \mathrm{N}$ (one grid distance south of the injection latitude for Mediterranean water). The straight lines indicate westward propagation with 0.12 and $0.57 \mathrm{~cm} \mathrm{~s}^{-1}$, respectively.

Arhan 1987). The direct effect of diapycnal processes on the (vertical) spreading of MW is small over the timescale (a few decades) of MW renewal. The indirect effect through changes in the density field and consequently the circulation also remains small in our examples. The cabbeling process is included in most realistic models of the Atlantic where, however, it is not known to be responsible for a significant increase in MW volume. Due to the design of our experiments we can easily extract the effect of cabbeling: From the comparison of the CABBEL and CABBEL-A experiments we can conclude that the density anomaly induced by cabbeling is likely to curtail the zonal spreading of MW while it increases the northward spreading.

An interior Sverdrup-like circulation spins up due to the vertical velocities associated with diapycnal mixing in the experiments DIFFUS and DDMIX. In both cases, the horizontal circulation carries MW northward along the eastern border while there is overall little westward transport of MW. Apparently this is due to an eastward velocity component that traps the MW near the coast. The lack of impact of diapycnal processes, especially of double diffusion, is partly due to the absence of a preexisting MW anomaly in the interior of the basin. When such a large-scale anomaly already exists, due to other processes like the mass exchange across the eastern boundary as in the INFLOW_DD experiment, double diffusion leads to a considerable northward and eastward redistribution of MW.

With isopycnal mixing and the weak mean flow that prevails in the outflow region, a spatial distribution of the MW anomaly is obtained that is inconsistent with observations due to the uniform spreading in all horizontal directions. Nonisotropic mixing associated with baroclinic instability as proposed by Spall (1994) could potentially resolve this problem. However, unrealistically high diffusion coefficients would be necessary to reproduce the observed salt flux into the Atlantic. Such 

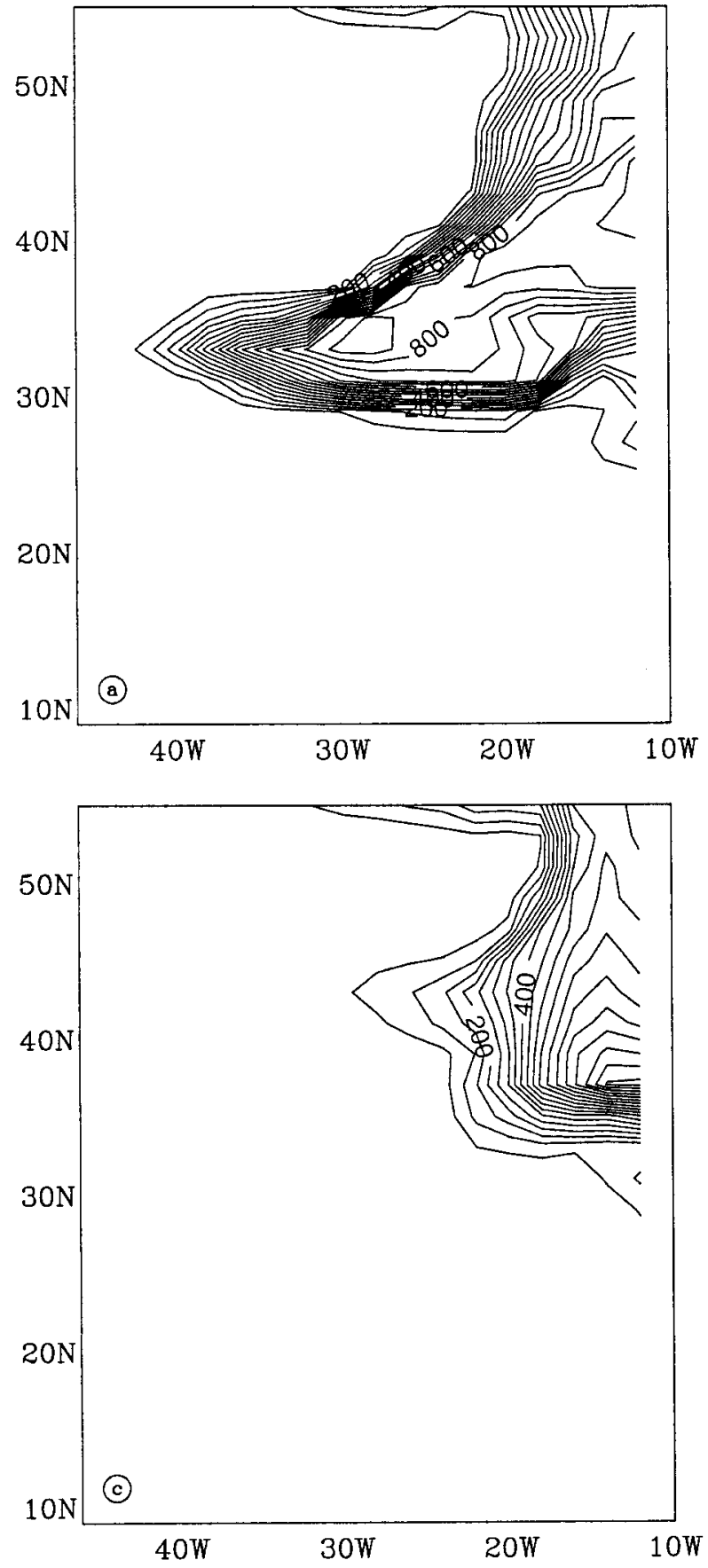

diffusion coefficients cannot be justified from the eddy kinetic energy and correlation length scales that are observed in the eastern subtropical North Atlantic. Käse and Zenk (1996) estimate that the salt flux divergence by mean currents at $20^{\circ} \mathrm{W}$ would lead to an increase of salinity by 1 psu in 30 years if not balanced by diffusion. The required isopycnal diffusion coefficient of $5 \times 10^{2}$ $\mathrm{m}^{2} \mathrm{~s}^{-1}$ is three times smaller than the coefficient (at 1200-m depth) employed in ISOPYC. Even with this

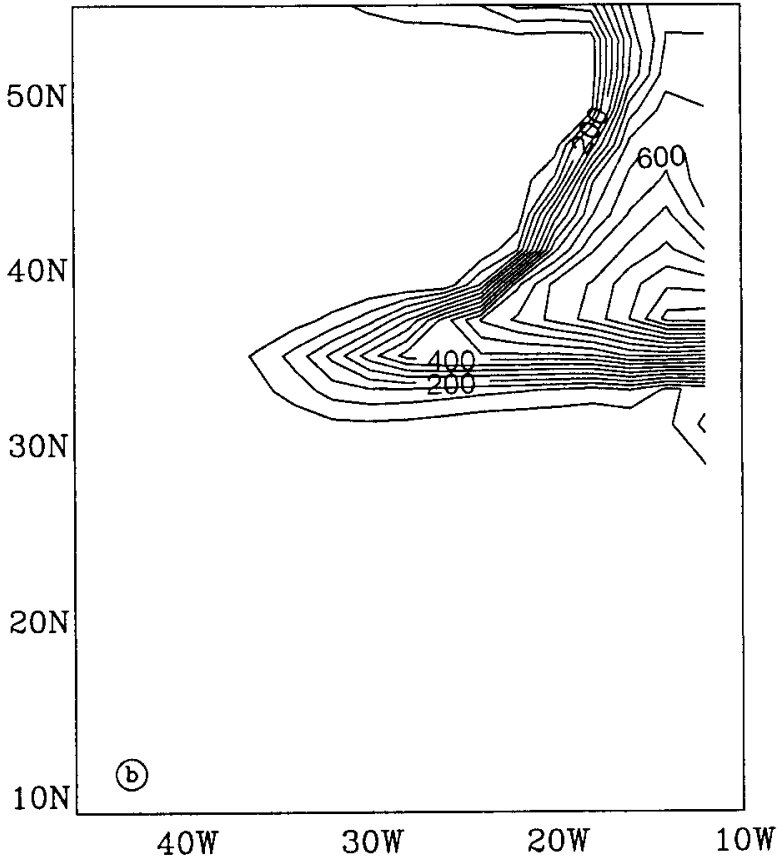

FIG. 11. Distributions of the MW tracer T3 at 1180-m depth for experiments (a) INFLOW-FCT, (b) INFLOW-DD, and (c) INFLOW-DD-A. Contour interval is 0.05 .

unrealistically large isopycnal mixing coefficients a salinity flux of only $15 \mathrm{Gt} / \mathrm{yr}$ results, roughly one-third of the actually observed flux.

The most important process in our experiments is the volume flux associated with the Atlantic-Mediterranean exchange. In the INFLOW experiments this exchange results in a westward current at and slightly south of the injection latitude that leads into a northward current $20^{\circ}$ of longitude away from the eastern boundary at the 
injection latitude and closer to the eastern boundary farther north. This current system that is established in response to the inflow carries a MW anomaly into the interior that is, considering the idealized nature of the model configuration, in good agreement with observations.

In summary, we find that the dynamic adjustment associated with the mass exchange through the eastern boundary dramatically improves the simulation of MW transport and interior distribution. This process does not depend on the presence of temperature and salinity anomalies in the inflow signal. Overall, we can conclude that the renewal and large-scale distribution of MW do not depend on the anomaly itself and that the MW anomaly can be regarded as mostly passive in our experiments. Processes that depend on the MW anomaly itself, like cabbeling and double diffusion, lead to a redistribution and larger northward transports of MW. However, compared to the current system associated with the inflow of MW, these processes must be regarded as second-order effects.

Acknowledgments. We thank an anonymous reviewer for the suggestion of adding the salt flux estimates of section 4 and other helpful comments.

\section{REFERENCES}

Arhan, M., 1987: On the large scale dynamics of the Mediterranean outflow. Deep-Sea Res., 34, 1187-1208.

—, A. Colin de Verdière, and L. Mémery, 1994: The eastern boundary of the subtropical North Atlantic. J. Phys. Oceanogr., 24, $1295-1316$.

Armi, L., and D. B. Haidvogel, 1982: Effects of variable and anisotropic diffusivities in a steady-state diffusion model. J. Phys. Oceanogr., 12, 785-794.

Beckmann, A., C. W. Böning, C. Köberle, and J. Willebrand, 1994 Effects of increased horizontal resolution in a simulation of the North Atlantic Ocean. J. Phys. Oceanogr., 24, 326-344.

Bryan, F. O., and W. R. Holland, 1989: A high resolution simulation of the wind- and thermohaline-driven circulation of the North Atlantic Ocean. Proc. 'Aha Huliko'a Hawaiian Winter Workshop, Hawaii, University of Hawaii at Manoa, 99-115.

Bryden, H. L., and T. H. Kinder, 1991: Steady two-layer exchange through the Strait of Gibraltar. Deep-Sea Res., 38, S445-S463.

Cox, M. D., 1987: Isopycnal diffusion in a z-coordinate ocean model. Ocean Modelling, (unpublished manuscripts), 74, 1-5.

— 1989: An idealized model of the world ocean. Part I: The global scale water masses. J. Phys. Oceanogr. 19, 1730-1752.

— mocline. J. Phys. Oceanogr., 14, 674-687.

Farrow, D. E., and D. P. Stevens, 1995: A new tracer advection scheme for Bryan and Cox type ocean general circulation models. $J$. Phys. Oceanogr., 25, 1731-1741.

Fukumori, I., 1991: Circulation about the Mediterranean tongue: An analysis of an EOF based model ocean. Progress in Oceanography, Vol. 27, Pergamon, 197-224.

Gargett, A. E., and G. Holloway, 1992: Sensitivity of the GFDL ocean model to different diffusivities for heat and salt. J. Phys. Oceanogr., 22, 1158-1177.

Gerdes, R., and C. Köberle, 1995: On the influence of DSOW in a numerical model of the North Atlantic general circulation. $J$. Phys. Oceanogr., 25, 2624-2642.

,$- \ldots$, and J. Willebrand, 1991: The influence of numerical advection schemes on the results of ocean general circulation models. Climate Dyn., 5, 211-226.

Hecht, M. W., W. R. Holland, and P. I. Rasch, 1995: Upwind-weighted advection schemes for ocean tracer transport: An evaluation in a passive tracer context. J. Geophys. Res., 100 (C10), $20763-$ 20778.

Hsieh, W. W., M. K. Davey, and R. Wajsowicz, 1983: Free Kelvin wave in finite-difference numerical model. J. Phys. Oceanogr., 13, 1383-1397.

Käse, R. H., and W. Zenk, 1987: Reconstructed Mediterranean salt lens trajectories. J. Phys. Oceanogr., 17, 158-163.

— , and — 1996: Structure of the Mediterranean Water and meddy characteristics in the Northeastern Atlantic. The Warmwatersphere of the North Atlantic Ocean, W. Krauss, Ed., Borntraeger, $446 \mathrm{pp}$.

Klinck, J. M., 1995: Thermohaline structure of an eddy-resolving North Atlantic model: The influence of boundary conditions. $J$. Phys. Oceanogr., 25, 1174-1195.

Levitus, S., 1982: Climatological Atlas of the World Ocean. NOAA Prof. Paper No. 13, U.S. Govt. Printing Office, 173 pp.

McCartney, M. S., and L. D., Talley, 1982: The subpolar mode water of the North Atlantic Ocean. J. Phys. Oceanogr., 12, 1169-1188.

McDougall, T. J., 1987: Thermobaricity, cabbeling, and water-mass conversion. J. Geophys. Res., 92 (C5), 5448-5464.

Ochoa, J., and N. A. Bray, 1991: Water mass exchange in the Gulf of Cadiz. Deep-Sea Res., 38 (Suppl.), S465-S503.

Pacanowski, R., K. Dixon, and A. Rosati, 1991: The G.F.D.L. modular ocean model users guide. GFDL Ocean Group Tech. Rep. No. 2, Geophysical Fluid Dynamics Laboratory/Princeton University, Princeton, NJ. [Available from Geophysical Fluid Dynamics Laboratory, P.O. Box 308, Princeton, NJ 08542.]

Prince, J. F., and M. O'Neill Baringer, 1994: Outflow and deep water production by marginal seas. Progress in Oceanography, Vol. 33, Pergamon, 161-200.

, T. K. McKee, J. R. Valdes, P. L. Richardson, and L. Armi, 1986: SOFAR float Mediterranean outflow experiment, 19841985. Woods Hole Oceanographic Institution Tech. Rep. WHOI86-31, 199 pp. [Available from Woods Hole Oceanographic Institution, Woods Hole, MA 02543.]

Redi, M. H., 1982: Oceanic isopycnal mixing by coordinate rotation. J. Phys. Oceanogr., 12, 1154-1158.

Reid, J. L., 1979: On the contribution of the Mediterranean Sea outflow to the Norwegian-Greenland Sea. Deep-Sea Res., 26A, $1199-1223$.

- 1994: On the total geostrophic circulation of the North Atlantic Ocean: Flow patterns, tracers, and transports. Progress in Oceanography, Vol. 33, Pergamon, 33, 1-92.

Richardson, P. L., D. Walsh, L. Armi, M. Schröder, and J. F. Price, 1989: Tracking three meddies with SOFAR floats. J. Phys. Oceanogr., 19, 371-383.

Ruddick, B., 1983: A practical indicator of the stability of the water column to double-diffusive activity. Deep-Sea Res., 30, 11051107.

Sarmiento, J. L., and K. Bryan, 1982: An ocean transport model for the North Atlantic. J. Geophys. Res., 87, 8047-8056.

Schmitt, R. W., 1979: Flux measurements on salt fingers at an interface. J. Mar. Res., 37, 419-436.

Schopp, R., and M. Arhan, 1986: Ventilated middepth circulation model for the eastern North Atlantic. J. Phys. Oceanogr., 16, 344-357.

Spall, M. A., 1990: Circulation in the Canary Basin: A model/data analysis. J. Geophys. Res., 95 (C6), 9611-9628.

_ 1994: Mechanism for low-frequency variability and salt flux in the Mediterranean salt tongue. J. Geophys. Res., 99 (C5), $10121-10129$.

Stanev, E. V., 1992: Numerical experiments on the spreading of Mediterranean water in the North Atlantic. Deep-Sea Res., 39, 17471766.

Turner, J. S., 1973: Buoyancy Effects in Fluids. Cambridge University Press, $367 \mathrm{pp}$ 
Tziperman, E., 1987: The Mediterranean outflow as an example of a deep buoyancy-driven flow. J. Geophys. Res., 92 (C13), 14 510-14 520.

Wijfels, S. E., R. W. Schmitt, H. L. Bryden, and A. Stigebrandt, 1992:
On the transport of fresh water by the oceans. J. Phys. Oceanogr., 22, $155-162$.

Zalesak, S. T., 1979: Fully multi-dimensional flux-corrected transport algorithms for fluids. J. Comput. Phys., 31, 335-362. 